\title{
Solvothermal Synthesis, Crystal Structure, and Characterization of a Heterometallic Iodoplumbate
}

\author{
Le-Qing Fan * (1) and Xiao-Tong Zhu \\ Engineering Research Center of Environment-Friendly Functional Materials, Ministry of Education, \\ College of Materials Science and Engineering, Huaqiao University, Xiamen 361021, China; zxtfjxm@163.com \\ * Correspondence: leqingfan@163.com; Tel.: +86-592-616-2225
}

Received: 28 June 2018; Accepted: 23 July 2018; Published: 25 July 2018

\begin{abstract}
The design and synthesis of heterometallic iodoplumbates have attracted much interest due to the diverse structures and significant physical properties. $\mathrm{A} \mathrm{Pb} / \mathrm{Cu}^{\mathrm{I}} / \mathrm{I}$ heterometallic iodoplumbate, $\left[\mathrm{PbCu}_{2} \mathrm{I}_{4}(\text { bipy) }]_{n}\right.$ (1) (bipy = 2,2'-bipyridine), has been synthesized by solvothermal reaction of $\mathrm{PbI}_{2}, \mathrm{Cu}\left(\mathrm{NO}_{3}\right)_{2}$, bipy, and $\mathrm{HI}$, and characterized by single-crystal X-ray diffraction, powder X-ray diffraction, and thermogravimetric analysis. This compound exhibits one-dimensional neutral structure, which is built upon the linkages of $\mathrm{Pb} / \mathrm{I}$ chains, $\mathrm{Cu} / \mathrm{I}$ chains, and $\mathrm{Cu}$ (bipy) units. The yellow compound has an optical bandgap of $2.32 \mathrm{eV}$ and shows fluorescent emission at $610 \mathrm{~nm}$ which is assigned to iodide-to-copper charge transfer.
\end{abstract}

Keywords: Heterometallic iodoplumbate; solvothermal synthesis; luminescence property; crystal structure

\section{Introduction}

Inorganic-organic hybrid iodoplumbates have greatly attracted scientists' attention in recent years due to their diverse structures and significant excitonic, nonlinear optical and other physical properties [1-7]. Their abundant structural diversity, including zero-dimensional clusters, infinite chains, layered perovskites, and three-dimensional polymeric networks, results from the flexibility of the $\mathrm{Pb}^{2+}$ coordination geometry and the characteristics of iodide anions [2,7-16]. The structures of iodoplumbates are usually made up of $\left[\mathrm{PbI}_{6}\right]$ octahedra by sharing vertexes, edges, or faces.

The introduction of heterometal (HM) ions into the structures of iodoplumbates is likely to produce novel structures as well as new physical properties, such as luminescence and magnetism. The general approach to synthesize heterometallic iodoplumbates is the employment of metal complex cations as templates, for example, $\left[\mathrm{M}(\mathrm{en})_{3}\right]^{2+}(\mathrm{en}=$ ethylenediamine, $\mathrm{M}=\mathrm{Cu}, \mathrm{Mn}, \mathrm{Fe}, \mathrm{Ni}),[17,18]$ $\left[\mathrm{Ln}(\mathrm{DMSO})_{8}\right]^{3+}\left(\mathrm{Ln}=\mathrm{La}, \mathrm{Pr}, \mathrm{Nd} ; \mathrm{DMSO}=\right.$ dimethyl sulfoxide) [19] and $\left[\mathrm{Cu}(\text { deta)I }]^{+}\right.$(deta = diethylene triamine) [20]. The results show that bivalent or trivalent metal ions can form such complex cations as templates. On the other hand, it is well known that $d^{10} \mathrm{Cu}^{+}$ions can exhibit outstanding luminescence properties [21]. However, its coordination fashion $\left(\left[\mathrm{CuI}_{4}\right]\right.$ tetrahedron) is evidently different from $\mathrm{Pb}^{2+}$. Therefore, it is meaningful to prepare $\mathrm{Pb} / \mathrm{Cu}^{\mathrm{I}} / \mathrm{I}$ heterometallic iodoplumbates for the possible formation of novel structures and physical properties. The approach mentioned above cannot be adopted to synthesize the goal compound because it is difficult for monovalent $\mathrm{Cu}^{+}$ions to form such complex cations. Therefore, our strategy is the fabrication of an inorganic-organic hybrid heterometallic iodoplumbate based on coordination compounds through the selection of a proper organic ligand which can join the $\mathrm{Pb} / \mathrm{I}$ backbone and $\mathrm{HM}$ ions or make the $\mathrm{Pb} / \mathrm{I} / \mathrm{HM}$ framework stable.

In this work, we report the synthesis, crystal structure, and characterization of $\mathrm{a} \mathrm{Pb} / \mathrm{Cu}^{\mathrm{I}} / \mathrm{I}$ heterometallic iodoplumbate $\left[\mathrm{PbCu}_{2} \mathrm{I}_{4}(\text { bipy) }]_{n}(\mathbf{1})\right.$, which was prepared under solvothermal conditions 
in the presence of the organic ligand bipy. This compound is one-dimensional neutral structure and has potential use as a semiconductor with good photoluminescence.

\section{Materials and Methods}

\subsection{Materials and Measurements}

All chemicals were obtained from Shanghai Aladdin Reagent (Shanghai, China) and were used without further purification. Powder X-ray diffraction (PXRD) data was tested on a DMAX2500 diffractometer (Rigaku, Tokyo, Japan). Thermogravimetric analysis (TGA) was performed on a Netzsch Sta449C thermoanalyzer (Netzsch, Saierbu, Germany) under $\mathrm{N}_{2}$ atmosphere in the temperature range of 30-800 ${ }^{\circ} \mathrm{C}$ at a heating rate of $10^{\circ} \mathrm{C} \mathrm{min}^{-1}$. Elemental analyses of carbon, hydrogen, and nitrogen were conducted using a Vario EL III (Elementar, Berlin, Germany) element analyzer. Diffuse reflectance spectra were measured at room temperature with a Perkin-Elmer Lambda35 UV-vis spectrometer (Perkin-Elmer, Waltham, MA, USA) equipped with an integrating sphere, and the $\mathrm{BaSO}_{4}$ plate was used as the reference. Fluorescence spectra were obtained at room temperature with the aid of an Edinburgh FLS920 fluorescence spectrophotometer (Edinburgh Instruments, Livingston, England) with the polycrystalline sample held between two pieces of fused silica slices. The crystal structure was determined by a Rigaku Mercury CCD area-detector diffractometer (Rigaku, Tokyo, Japan) and SHELXL-97 crystallographic software of molecular structure.

\subsection{Preparation of $\left[\mathrm{PbCu} \mathrm{I}_{4}(\text { bipy })\right]_{n}$ (1)}

A mixture of $\mathrm{PbI}_{2}$ (23 mg, $\left.0.5 \mathrm{mmol}\right), 2,2^{\prime}$-bipyridine (156 mg, $\left.1 \mathrm{mmol}\right), \mathrm{Cu}\left(\mathrm{NO}_{3}\right)_{2} \cdot 3 \mathrm{H}_{2} \mathrm{O}(482 \mathrm{mg}$, $2 \mathrm{mmol}), \mathrm{HI}$ acid $(1 \mathrm{~mL}), \mathrm{EtOH}(5 \mathrm{~mL})$, and $\mathrm{H}_{2} \mathrm{O}(5 \mathrm{~mL})$ was transferred into a Teflon-lined autoclave $(23 \mathrm{~mL})$, heated at $443 \mathrm{~K}$ for $4 \mathrm{~d}$ and then cooled at a rate of $2 \mathrm{~K} \mathrm{~h}^{-1}$ to room temperature. Yellow crystals suitable for X-ray diffraction analysis were obtained by filtration, washed with distilled water, and dried in air (42\% yield based on Pb). Anal. Calcd for $\mathbf{1}$ (dried) (\%): $\mathrm{C}, 12.03 ; \mathrm{H}, 0.81 ; \mathrm{N}, 2.81$. Found: $\mathrm{C}$, $12.31 ; \mathrm{H}, 0.99 ; \mathrm{N}, 2.63$. To evaluate the phase purity of the as-synthesized sample, the collected sample was characterized by PXRD at room temperature. The PXRD pattern for the product is consistent with the pattern derived from the single-crystal X-ray solution in position (Figure S1), indicating that our collected sample is pure and can be used in other tests.

\subsection{X-ray Crystallography}

The crystallographic data for 1 were collected on a Rigaku Mercury CCD area-detector equipped with a graphite-monochromated Mo K $\alpha$ radiation $(\lambda=0.71073 \AA)$ at $293(2) \mathrm{K}$ using an $\omega-2 \theta$ scan mode. Multi-scan absorption correction was conducted by the CrystalClear program [22]. The structure was solved by direct methods using the SHELXS-97 program and refined by full-matrix least-squares refinement on $F^{2}$ with the aid of the SHELXL-97 program [23,24]. All $\mathrm{H}$ atoms were positioned geometrically and refined as riding atoms. Data collection and refinements of this compound are listed in Table 1. Selected bond lengths and bond angles of $\mathbf{1}$ are gathered in Table 2.

Table 1. Crystallographic data and structure refinement parameters for $\mathbf{1}$.

\begin{tabular}{cc}
\hline Molecular Formula & $\mathbf{C}_{\mathbf{1 0}} \mathbf{H}_{\mathbf{8}} \mathbf{C} \mathbf{u}_{\mathbf{2}} \mathbf{I}_{\mathbf{4}} \mathbf{N}_{\mathbf{2}} \mathbf{P b}$ \\
\hline Formula weight & 998.05 \\
Temperature (K) & $293(2)$ \\
Wavelength $(\AA)$ & 0.71073 \\
Crystal system & Triclinic \\
Space group & $P \overline{1}$ \\
$a(\AA)$ & $4.2520(4)$ \\
$b(\AA)$ & $13.1554(8)$ \\
$c(\AA)$ & $16.4353(15)$ \\
\hline
\end{tabular}


Table 1. Cont.

\begin{tabular}{cc}
\hline Molecular Formula & $\mathbf{C}_{\mathbf{1 0}} \mathbf{H}_{\mathbf{8}} \mathbf{C u}_{\mathbf{2}} \mathbf{I}_{\mathbf{4}} \mathbf{N}_{\mathbf{2}} \mathbf{P b}$ \\
\hline$\alpha\left(^{\circ}\right)$ & $98.231(6)$ \\
$\beta\left(^{\circ}\right)$ & $94.171(8)$ \\
$\gamma\left(^{\circ}\right)$ & $96.090(7)$ \\
$\mathrm{V}\left(\AA^{\circ}\right)$ & $901.11(13)$ \\
$\mathrm{Z}$ & 2 \\
$D_{\text {calc }}\left(\mathrm{g} \cdot \mathrm{cm}^{-3}\right)$ & 3.678 \\
$\mu\left(\mathrm{mm}^{-1}\right)$ & 18.497 \\
$F(000)$ & 868 \\
Crystal size $(\mathrm{mm})$ & $0.3 \times 0.15 \times 0.15$ \\
& $-5 \leq h \leq 5$, \\
Index range & $-16 \leq k \leq 17$, \\
Reflections collected & $-19 \leq l \leq 22$ \\
Independent reflections & 7013 \\
$\mathrm{R}_{\text {int }}$ & 4124 \\
$\theta$ range $\left({ }^{\circ}\right)$ & 0.0388 \\
Data $/$ restraints $/$ parameters & 2.76 to 29.31 \\
Goodness-of-fit on $F^{2}$ & $172 / 0 / 3056$ \\
Final $\mathrm{R}_{1}, w \mathrm{R}_{2}$ indices & 1.028 \\
$\mathrm{R}_{1}{ }^{a}, w \mathrm{R}_{2}{ }^{b}$ indices $($ all data $)$ & $\mathrm{R}_{1}=0.0444, w \mathrm{R}_{2}=0.0855$ \\
Largest differences peak and hole $\left(\mathrm{e} \AA^{-3}\right)$ & $\mathrm{R}_{1}=0.0674, w \mathrm{R}_{2}=0.0999$ \\
\hline$a . R_{1}=\Sigma|| F_{0}|-| F_{\mathrm{c}}|| / \Sigma\left|F_{0}\right|, b . w R_{2}=\left[\Sigma w\left(\mathrm{~F}_{0}{ }^{2}-\mathrm{F}_{\mathrm{c}}{ }^{2}\right)^{2} / \Sigma w\left(\mathrm{~F}_{0}{ }^{2}\right)^{2}\right]^{1 / 2}$.
\end{tabular}

Table 2. Selected bond lengths $(\AA)$ and bond angles $\left(^{\circ}\right)$ for $\mathbf{1}$.

\begin{tabular}{cccccc}
\hline Bond & Lengths & Bond & Lengths & Bond & Lengths \\
\hline $\mathrm{Pb} 1-\mathrm{I} 2$ & $3.0679(8)$ & $\mathrm{Pb} 1-\mathrm{I} 1$ & $3.1217(9)$ & $\mathrm{Pb} 1-\mathrm{I} 2 A$ & $3.1679(9)$ \\
$\mathrm{Pb} 1-\mathrm{I} 4$ & $3.2279(9)$ & $\mathrm{Pb} 1-\mathrm{I} 4 A$ & $3.3514(9)$ & $\mathrm{Pb} 1-\mathrm{I} 3$ & $3.3515(9)$ \\
$\mathrm{Cu} 1-\mathrm{N} 1$ & $2.026(9)$ & $\mathrm{Cu} 1-\mathrm{N} 2$ & $2.076(11)$ & $\mathrm{Cu} 1-\mathrm{I} 1 B$ & $2.5635(17)$ \\
$\mathrm{Cu} 1-\mathrm{I} 1$ & $2.6713(19)$ & $\mathrm{Cu} 2-\mathrm{I} 4$ & $2.6012(17)$ & $\mathrm{Cu}-\mathrm{I} 3 \mathrm{C}$ & $2.6557(19)$ \\
$\mathrm{Cu} 2-\mathrm{I} 3$ & $2.6603(18)$ & $\mathrm{Cu}-\mathrm{I} 3 B$ & $2.6807(16)$ & & \\
\hline Bond & Angles & Bond & Angles & Bond & Angles \\
\hline $\mathrm{I} 2-\mathrm{Pb} 1-\mathrm{I} 1$ & $87.33(2)$ & $\mathrm{I} 4-\mathrm{Pb} 1-\mathrm{I} 4 A$ & $80.50(2)$ & $\mathrm{N} 1-\mathrm{Cu} 1-\mathrm{I} 1$ & $98.7(3)$ \\
$\mathrm{I} 2-\mathrm{Pb} 1-\mathrm{I} 2 A$ & $85.96(2)$ & $\mathrm{I}-\mathrm{Pb} 1-\mathrm{I} 3$ & $84.58(2)$ & $\mathrm{N} 2-\mathrm{Cu} 1-\mathrm{I} 1$ & $128.4(3)$ \\
$\mathrm{I} 1-\mathrm{Pb} 1-\mathrm{I} 2 A$ & $104.78(3)$ & $\mathrm{I} 1-\mathrm{Pb} 1-\mathrm{I} 3$ & $167.95(2)$ & $\mathrm{I} 1 B-\mathrm{Cu} 1-\mathrm{I} 1$ & $108.62(6)$ \\
$\mathrm{I} 2-\mathrm{Pb} 1-\mathrm{I} 4$ & $97.23(2)$ & $\mathrm{I} 2 A-\mathrm{Pb} 1-\mathrm{I} 3$ & $83.59(2)$ & $\mathrm{I} 4-\mathrm{Cu} 2-\mathrm{I} 3 B$ & $108.63(6)$ \\
$\mathrm{I} 1-\mathrm{Pb} 1-\mathrm{I} 4$ & $89.98(2)$ & $\mathrm{I} 4-\mathrm{Pb} 1-\mathrm{I} 3$ & $82.20(2)$ & $\mathrm{I} 4-\mathrm{Cu}-\mathrm{I} 3$ & $110.62(6)$ \\
$\mathrm{I} 2 A-\mathrm{Pb} 1-\mathrm{I} 4$ & $165.06(3)$ & $\mathrm{I} 4 A-\mathrm{Pb} 1-\mathrm{I} 3$ & $81.38(2)$ & $\mathrm{I} 3 \mathrm{C}-\mathrm{Cu} 2-\mathrm{I} 3$ & $114.96(6)$ \\
$\mathrm{I} 2-\mathrm{Pb} 1-\mathrm{I} 4 A$ & $165.96(3)$ & $\mathrm{N} 1-\mathrm{Cu} 1-\mathrm{N} 2$ & $81.1(4)$ & $\mathrm{I}-\mathrm{Cu}-\mathrm{I} 3 B$ & $111.65(6)$ \\
$\mathrm{I} 1-\mathrm{Pb} 1-\mathrm{I} 4 A$ & $106.46(2)$ & $\mathrm{N} 1-\mathrm{Cu} 1-\mathrm{I} 1 B$ & $130.6(3)$ & $\mathrm{I} B C-\mathrm{Cu}-\mathrm{I} 3 B$ & $105.35(6)$ \\
$\mathrm{I} 2 A-\mathrm{Pb} 1-\mathrm{I} 4 A$ & $92.85(2)$ & $\mathrm{N} 2-\mathrm{Cu} 1-\mathrm{I} 1 B$ & $109.8(3)$ & $\mathrm{I}-\mathrm{Cu} 2-\mathrm{I} 3 B$ & $105.52(6)$ \\
\hline
\end{tabular}

Symmetry transformation used to generate equivalent atoms: $A: 1+x, y, z ; B:-1+x, y, z ; C: 1-x,-y,-z$.

Crystallographic data have been deposited with the Cambridge Crystallographic Data Centre as supplementary publication, with CCDC-1846939 for $\mathbf{1}$. Copies of the data can be obtained free of charge on application to CCDC, 12 Union Road, Cambridge CB21EZ, UK (Telephone: +(44)-0123-7629120; Fax: +44-1223-336033; E-mail: deposit@ccdc.cam.ac.uk). These data can be also obtained free of charge at www.ccdc.cam.ac.uk/conts / retrieving.html. 


\section{Results and Discussion}

\subsection{Synthesis}

Compound 1 was prepared from the reaction mixture of $\mathrm{PbI}_{2}, \mathrm{Cu}\left(\mathrm{NO}_{3}\right)_{2}$, bipy, and $\mathrm{HI}$ in the mixed solvents of water and ethanol at $170{ }^{\circ} \mathrm{C}$ through the solvothermal method. The results indicate that the $\mathrm{Cu}$ atoms in this compound are monovalent. However, a reactant containing monovalent $\mathrm{Cu}$ was not used; therefore, the production of $\mathrm{Cu}^{\mathrm{I}}$ could be attributed to the reduction of bivalent $\mathrm{Cu}^{2+}$ by $\mathrm{I}^{-}$under this solvothermal conditions. When $\mathrm{CuI}$ taking place of $\mathrm{Cu}\left(\mathrm{NO}_{3}\right)_{2}$ was directly used as reactant, crystal suitable for $\mathrm{X}$-ray single-crystal analysis was not obtained. Lots of experiments using $\mathrm{Cl}^{-}$or $\mathrm{Br}^{-}$ions as halide sources in place of $\mathrm{I}^{-}$, and other organic ligand such as 1,10-phenanthroline instead of bipy under the same condition have also been done to synthesize compounds similar structurally to 1 , but unfortunately, we did not succeed.

\subsection{Structure Description}

This compound was synthesized under solvothermal conditions and crystallized in the space group $P \overline{1}$. The asymmetric unit of $\mathbf{1}$ consists of one $\mathrm{Pb}$ atom, two $\mathrm{Cu}$ atoms, four I atoms, and one bipy ligand. As shown in Figure 1, the Pb1 atom is surrounded by six I atoms in a familiar $\left[\mathrm{Pb}_{6} \mathrm{I}_{6}\right]$ octahedral environment. The Pb-I distances vary from 3.0679(8) to 3.3515(9) $\AA$ (Table 2) and are in accordance with those in many reported iodoplumbates $[25,26]$. The cis I-Pb-I angles are between 80.50(2) and $106.46(2)^{\circ}$, which deviate from the ideal $90^{\circ}$. Based on the charge balance of this structure, $\mathrm{Cu} 1$ and $\mathrm{Cu} 2$ are assigned as monovalent, which is also supported by the bond-valence sum (BVS) calculations, the valences of atoms $\mathrm{Cu} 1$ and $\mathrm{Cu} 2$ are 1.03 and 0.98 , respectively. Bipy acts as a chelating ligand which bonds to the $\mathrm{Cu} 1$ atom by its two $\mathrm{N}$ atoms. At the same time, the $\mathrm{Cu} 1$ atom is bonded to two I atoms. As a consequence, the $\mathrm{Cu} 1$ atom exhibits $\left[\mathrm{Cu}_{1} \mathrm{~N}_{2} \mathrm{I}_{2}\right]$ tetrahedral coordination. Different from the $\mathrm{Cu} 1$ atom, the $\mathrm{Cu} 2$ atom is coordinated by four $\mathrm{I}$ atoms in a $\left[\mathrm{Cu} 2 \mathrm{I}_{4}\right]$ tetrahedral geometry. The $\mathrm{Cu}-\mathrm{N}$ distances are 2.026(9) $\AA$ and 2.076(11) $\AA$, and the $\mathrm{Cu}-\mathrm{I}$ distances are from 2.5635(17) $\AA$ to $2.6807(16) \AA$. [ $\left.\mathrm{Pb} 1 \mathrm{I}_{6}\right]$ octahedra are joined by common edges (I2-I4) to form $\mathrm{PbI}_{6}$ chain. $\left[\mathrm{Cu}_{4} \mathrm{I}_{4}\right]$ tetrahedra link each other by sharing edges (I3-I3) to engender $\mathrm{CuI}_{4}$ chain. The $\mathrm{Cu} 2 \cdots \mathrm{Cu} 2$ distance of 2.858(3) $\AA$, which is longer than the double van der Waals radius of the $\mathrm{Cu}^{+}$ion $(1.4 \AA)$, implies a weak $\mathrm{Cu} \cdots \mathrm{Cu}$ interaction. The $\mathrm{CuI}_{4}$ chain connects two adjacent $\mathrm{PbI}_{6}$ chains through common edges (I3-I4) to produce $\mathrm{Pb} / \mathrm{Cu} / \mathrm{I}$ chain, which is further linked to $\left[\mathrm{Cu}_{1} \mathrm{~N}_{2} \mathrm{I}_{2}\right]$ tetrahedra by vertex sharing (I1) to give rise to one-dimensional ribbon-like neutral structure $\left[\mathrm{PbCu}_{2} \mathrm{I}_{4}(\text { bipy) }]_{n}\right.$ along the $a$ axis (Figures 2 and 3). No distinct interaction is found between neighboring ribbons. As a result of the connectivity of the $\left[\mathrm{Pb}_{1} \mathrm{I}_{6}\right]$ octahedra and $\left[\mathrm{Cu}_{1} \mathrm{~N}_{2} \mathrm{I}_{2}\right]$ and $\left[\mathrm{Cu} 2 \mathrm{I}_{4}\right]$ tetrahedra, the iodide ligands act as $\mu_{2^{-}}$(I2), $\mu_{3^{-}}$(I1 and I4), and $\mu_{4}$-bridging (I3) ligands.

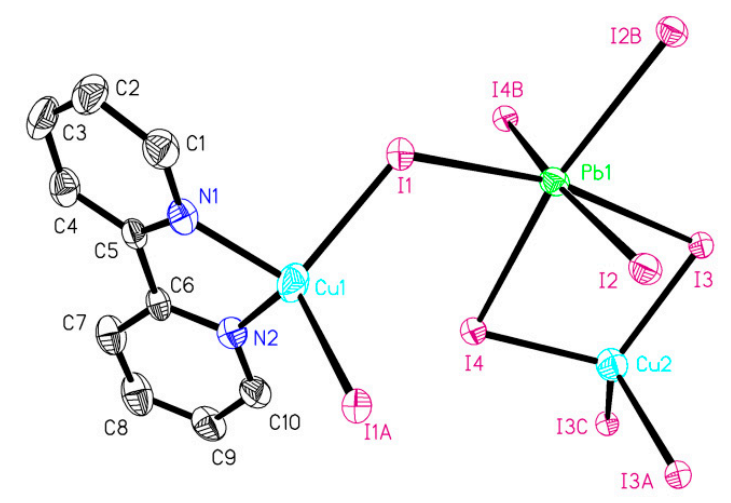

Figure 1. The coordination environment of the $\mathrm{Pb}$ and $\mathrm{Cu}$ atoms in $\mathbf{1}$. All $\mathrm{H}$ atoms have been omitted for clarity. Displacement ellipsoids are depicted at the 30\% probability level. Symmetry codes: A: $-1+$ $x, y, z ; \mathrm{B}: 1+x, y, z ; \mathrm{C}: 1-x,-y,-z$. 


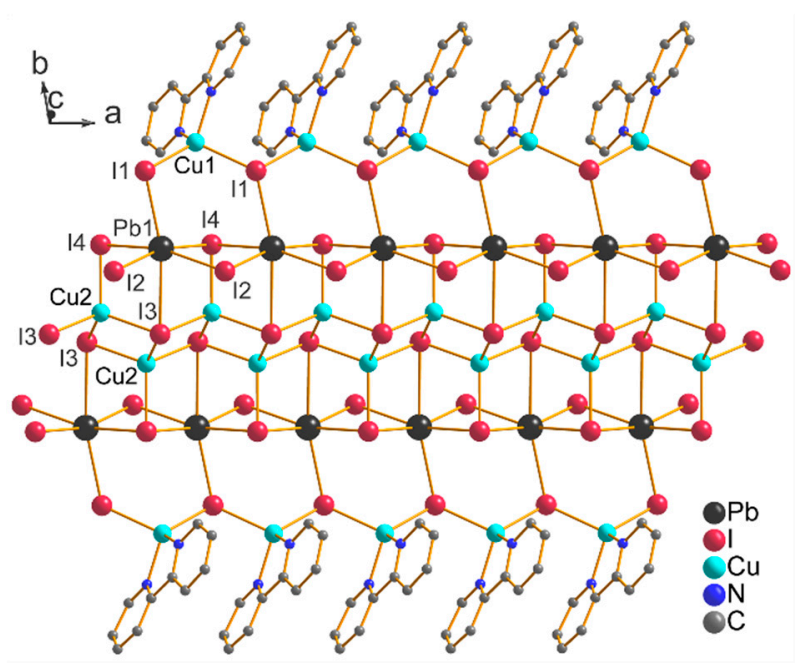

Figure 2. The fragment of the structure of $\mathbf{1}$ extending along the $a$ axis. All $\mathrm{H}$ atoms have been omitted for clarity.

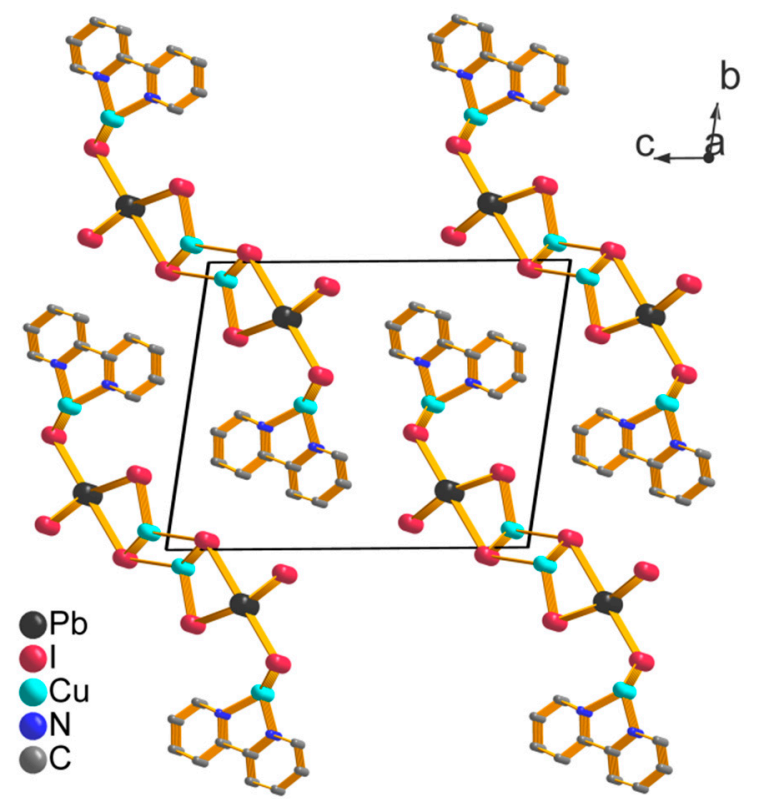

Figure 3. Packing diagram of 1. All $\mathrm{H}$ atoms have been omitted for clarity.

\subsection{Thermal Stability}

To evaluate the thermal stability of this material, TGA was conducted on the collected powder sample in $\mathrm{N}_{2}$ atmosphere from $30^{\circ} \mathrm{C}$ to $800{ }^{\circ} \mathrm{C}$. TGA reveals that the weight loss in $\mathbf{1}$ begins at ca. $200{ }^{\circ} \mathrm{C}$ up to ca. $395{ }^{\circ} \mathrm{C}$ to give a weight loss of $15.3 \%$, corresponding to the loss of one bipy molecule per formula unit (15.6\% calculated). In the subsequent weight loss, this compound continues to gradually decompose (Figure S2).

\subsection{Diffuse Reflectance Spectroscopy}

In order to obtain the optical band gap of $\mathbf{1}$, its diffuse reflectance spectroscopy was measured. With the help of the Kubelka-Munk function: $F(R)=(1-R)^{2} / 2 R$, in which $R$ is the experimentally observed reflectance $[27,28]$, the plot of $F(R)^{2}$ vs. photon energy was obtained and is presented in Figure 4. In this plot, the optical band gap is determined by extending the linear portion of the absorption edge to intersect the energy axis. The produced intersection demonstrates that the 
optical band gap of $\mathbf{1}$ is $2.32 \mathrm{eV}$, which is consistent with its yellow color, showing the potential use as semiconductor.

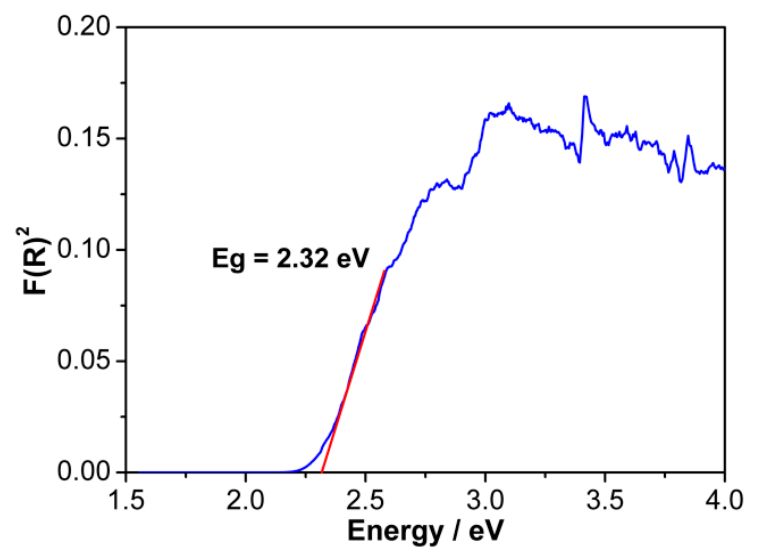

Figure 4. Plot of $F(R)^{2}$ vs. photon energy for 1 .

\subsection{Luminescence Property}

As reported in many studies, $d^{10} \mathrm{Cu}^{+}$ions present outstanding luminescence properties. To investigate the luminescence property of $\mathbf{1}$, its fluorescence spectrum was measured in the solid state at room temperature (Figure 5). Under excitation at $316 \mathrm{~nm}$, a fluorescent emission peak with an intense emission center at $610 \mathrm{~nm}$ appeared. According to the reported results of the similar copper(I) halide compounds, the emission band might be assigned to iodide-to-copper charge transfer $[29,30]$. This result indicates that this compound has potential as a luminescence material.

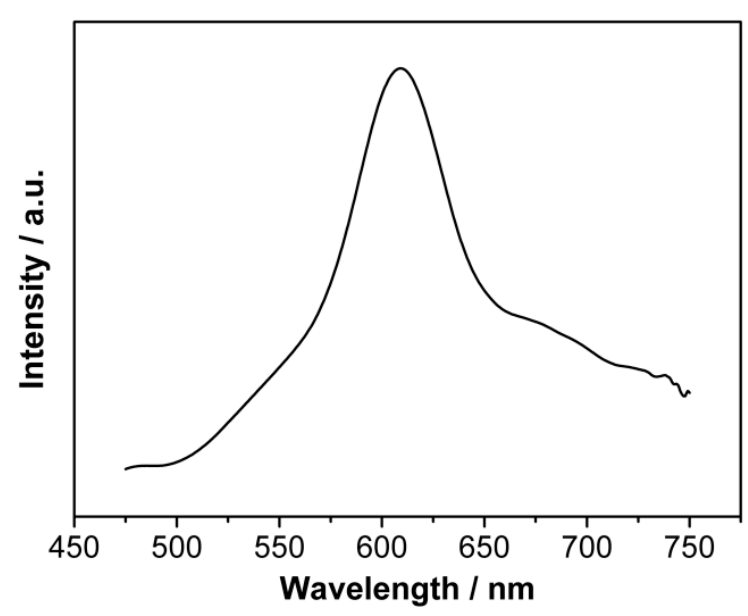

Figure 5. Solid-state emission spectrum for 1 at room temperature (excited at $316 \mathrm{~nm}$ ).

\section{Conclusions}

In conclusion, a $\mathrm{Pb} / \mathrm{Cu}^{\mathrm{I}} / \mathrm{I}$ heterometallic iodoplumbate has been prepared by a solvothermal method in presence of the organic ligand bipy. The semiconducting and luminescence properties of $\mathbf{1}$ are reported. The successful synthesis of $\mathbf{1}$ shows that the construction of an inorganic-organic heterometallic iodoplumbate based on coordination compounds can be achieved by choosing a proper organic ligand and controlling the synthesis conditions.

Supplementary Materials: The following are available online at http://www.mdpi.com/2073-4352/8/8/305/s1, Figure S1: Experimental and simulated powder X-ray diffraction patterns of 1, Figure S2: TGA curve of $\mathbf{1}$. 
Author Contributions: Le-Qing Fan designed the experiments and wrote the paper; Xiao-Tong Zhu performed the experiments and analyzed the data.

Funding: This work was supported financially by the National Natural Science Foundation of China (21301060), the Natural Science Foundation of Fujian Province (2017J01084), the Program for New Century Excellent Talents in Fujian Province University (2014FJ-NCET-ZR02), the Scientific Research Foundation for the Returned Overseas Chinese Scholars, State Education Ministry.

Conflicts of Interest: The authors declare no conflict of interest.

\section{References}

1. Mitzi, D.B. Templating and structural engineering in organic-inorganic perovskites. J. Chem. Soc. Dalton Trans. 2001, 1-12. [CrossRef]

2. Zhao, S.-P.; Ren, X.-M. Toward design of multiple-property inorganic-organic hybrid compounds based on face-sharing octahedral iodoplumbate chains. Dalton Trans. 2011, 40, 8261-8272. [CrossRef] [PubMed]

3. Usoltsev, A.N.; Adonin, S.A.; Abramov, P.A.; Korolkov, I.V.; Yushina, I.V.; Antonova, O.V.; Sokolov, M.N.; Fedin, V.P. Polymeric hybrid iodoplumbates and iodobismuthates containing mono- and bisalkylated derivatives of 1,2-bis(4-pyridyl)ethylene: Structural and optical features. Inorg. Chim. Acta 2017, 462, 323-328. [CrossRef]

4. Fan, L.-Q.; Wu, L.-M.; Chen, L. Syntheses, crystal structures, and properties of heterometallic iodoplumbates: Bicubane, ribbon, and chain configurations. Inorg. Chem. 2006, 45, 3149-3151. [CrossRef] [PubMed]

5. Wang, Y.; Zhang, J.; Huang, J.; Zhang, H.; Fu, Z. A lead-iodide based single crystal semiconductor: Exploring multi-orientation photoconductive behaviour via intervening isopropyl viologen component between the inorganic $\left[\mathrm{Pb}_{2} \mathrm{I}_{6}\right]^{2-}{ }_{n}$ wires. CrystEngComm 2018, 20, 2089-2092. [CrossRef]

6. Payheghader, M.; Morsali, A.; Hertle, I.; Kempe, R. $\left[\mathrm{Pb}_{2}(\mathrm{AMP})_{2}(\mu-\mathrm{X})_{2} \mathrm{X}_{2}\right], \mathrm{X}=\mathrm{Br}^{-}$and I $\mathrm{I}^{-}, \mathrm{AMP}=$ 2-aminomethylpyridine, two new dimeric lead(ii) complexes extended in one-dimensional helical chain polymers by noncovalent $\pi-\pi$-stacking. Z. Anorg. Allg. Chem. 2005, 631, 943-946. [CrossRef]

7. Xue, Y.-Y.; Zhang, L.-X.; Li, S.-N.; Jiang, Y.-C.; Hu, M.-C.; Zhai, Q.-G. Ionothermal synthesis of novel $\mathrm{Pb}-\mathrm{OH}-\mathrm{Cu}-\mathrm{X}(\mathrm{X}=\mathrm{Cl}, \mathrm{Br}$ and $\mathrm{I})$ quaternary heterometallic frameworks with tunable optical properties. Dalton Trans. 2017, 46, 5183-5188. [CrossRef] [PubMed]

8. Aslani, A.; Morsali, A. Sonochemical synthesis of nano-sized metal-organic lead(II) polymer: A precursor for the preparation of nano-structured lead(II) iodide and lead(II) oxide. Inorg. Chim. Acta 2009, 362, 5012-5016. [CrossRef]

9. Lemmerer, A.; Billing, D.G. Lead halide inorganic-organic hybrids incorporating diammonium cations. CrystEngComm 2012, 14, 1954-1966. [CrossRef]

10. Fan, L.-Q.; Wu, J.-H. Novel lead iodine dialkyldithiocarbamates with different dimensions: $\left[\mathrm{PbI}\left(\mathrm{S}_{2} \mathrm{CNR}_{2}\right)\right]_{n}$ $\left(\mathrm{R}_{2}=\mathrm{Me}_{2},\left(\mathrm{CH}_{2}\right)_{4}\right.$, and $\left.\left(\mathrm{CH}_{2}\right)_{5}\right)$. Inorg. Chem. Commun. 2015, 57, 72-74. [CrossRef]

11. Wang, G.-E.; Xu, G.; Liu, B.-W.; Wang, M.-S.; Yao, M.-S.; Guo, G.-C. Semiconductive nanotube array constructed from giant $\left[\mathrm{Pb}^{\mathrm{II}}{ }_{18} \mathrm{I}_{54}\left(\mathrm{I}_{2}\right)_{9}\right]$ wheel clusters. Angew. Chem. Int. Ed. 2016, 55, 514-518. [CrossRef] [PubMed]

12. Wu, L.-M.; Wu, X.-T.; Chen, L. Structural overview and structure-property relationships of iodoplumbate and Iodobismuthate. Coord. Chem. Rev. 2009, 253, 2787-2804. [CrossRef]

13. Zhang, Z.-J.; Xiang, S.-C.; Zhang, Y.-F.; Wu, A.-Q.; Cai, L.-Z.; Guo, G.-C.; Huang, J.-S. A new type of hybrid magnetic semiconductor based upon polymeric iodoplumbate and metal-organic complexes as templates. Inorg. Chem. 2006, 45, 1972-1977. [CrossRef] [PubMed]

14. Hartl, H.; Hoyer, M. Synthesis and structure investigations of iodocuprates(I), XVIII. preparation and crystal structure of $\mathrm{PbCu}_{2} \mathrm{I}_{4} \cdot 2 \mathrm{CH}_{3} \mathrm{CN}$. Z. Naturforsch. B 2014, 52, 766-768. [CrossRef]

15. Kelly, A.W.; Wheaton, A.M.; Nicholas, A.D.; Barnes, F.H.; Patterson, H.H.; Pike, R.D. Iodobismuthate(III) and iodobismuthate(iii)/iodocuprate(i) complexes with organic ligands. Eur. J. Inorg. Chem. 2017, 4990-5000. [CrossRef]

16. Adonin, S.A.; Sokolov, M.N.; Smolentsev, A.I.; Kozlova, S.G.; Fedin, V.P. $\left[\mathrm{PtBi}_{2} \mathrm{I}_{12}\right]^{2-}$ : The first polyiodobismuthate containing an octahedral heterometallic unit. Dalton Trans. 2013, 42, 9818-9821. [CrossRef] [PubMed] 
17. Zhang, Z.-J.; Xiang, S.-C.; Guo, G.-C.; Xu, G.; Wang, M.-S.; Zou, J.-P.; Guo, S.-P.; Huang, J.-S. Wavelength-dependent photochromic inorganic-organic hybrid based on a 3D iodoplumbate open-frameworkmaterial. Angew. Chem. Int. Ed. 2008, 47, 4149-4152. [CrossRef] [PubMed]

18. Li, H.-H.; Sun, L.-G.; Chen, Z.-R.; Wang, Y.-J.; Li, J.-Q. Incorporating a transition metal complex into polymeric iodoplumbate: Structure characterization, properties and theoretical study of a unprecedented hybrid semiconductor: $\left\{\left[\mathrm{Cu}(\mathrm{en})_{2}\right]\left[\mathrm{Pb}_{2} \mathrm{I}_{6}\right]\right\}_{n}$. Aust. J. Chem. 2008, 61, 391-396. [CrossRef]

19. Tang, C.; Wang, F.; Jia, D.; Jiang, W.; Zhang, Y. Syntheses and characterizations of polymeric silver iodoplumbates, and iodoplumbates with lanthanide complexes. CrystEngComm 2014, 16, 2016-2024. [CrossRef]

20. Li, H.; Chen, Z.; Li, J.; Huang, C.; Xiao, G.; Zhao, B. Structure and self-assembly synthesis of a novel heterometallic one-dimensional coordination polymer: $\left\{[\mathrm{Cu}(\mathrm{II})(\mathrm{DETA}) \mathrm{I} \cdot \mathrm{DMF}]_{2}\left[\mathrm{~Pb}_{2} \mathrm{I}_{6}\right]\right\}_{n}$. J. Chem. Crystallogr. 2006, 36, 419-425. [CrossRef]

21. Ma, Y.; Du, L.; Wang, K.; Zhao, Q. Synthesis, crystal structure, luminescence and magnetism of three novel coordination polymers based on flexible multicarboxylate zwitterionic ligand. Crystals 2017, 7, 32. [CrossRef]

22. Rigaku. CrystalClear; Rigaku Corporation: Tokyo, Japan, 2007.

23. Sheldrick, G.M. SHELXS-97, Program for the Solution of Crystal Structures; University of Göttingen: Göttingen, Germany, 1997.

24. Sheldrick, G.M. SHELXL-97, Program for the Refinement of Crystal Structures; University of Göttingen: Göttingen, Germany, 1997.

25. Fan, L.-Q.; Jin, X.; Li, D.-X.; Tian, C.-B.; Wu, J.-H. $\left.\left[\mathrm{Pb}_{3} \mathrm{Cu}_{2} \mathrm{I}_{10} \text { (phen) }\right)_{4}\right]_{n}$ : A novel organic-inorganic hybrid ferromagnetic semiconductor. Dalton Trans. 2017, 46, 14738-14741. [CrossRef] [PubMed]

26. Hu, F.; Zhai, Q.-G.; Li, S.-N.; Jiang, Y.-C.; Hu, M.-C. Ionothermal synthesis of a new $(4,12)$-connected heterometallic iodoplumbate with $\left[\mathrm{Pb}_{4}(\mathrm{OH})_{4}\right]$ cubane as joint points of the helices. CrystEngComm 2011, 13, 414-417. [CrossRef]

27. Wendlandt, W.W.; Hencht, H.G. Reflectance Spectroscopy; Interscience Publishers: New York, NY, USA, 1966.

28. Kotüm, G. Reflectance Spectroscopy; Springer: New York, NY, USA, 1969.

29. Troyano, J.; Perles, J.; Amo-Ochoa, P.; Zamora, F.; Delgado, S. Strong luminescent copper(I) halide coordination polymers and dinuclear complexes with thioacetamide and $\mathrm{N}, \mathrm{N}^{\prime}$-donor ligands. CrystEngComm 2016, 18, 1809-1817. [CrossRef]

30. Fan, L.-Q.; Wu, J.-H.; Huang, Y.-F.Z. Two 2D 3d-4f Heterometallic coordination polymers with $\left[\mathrm{Ln}_{2}(\mathrm{IN})_{6}(\mathrm{OH})\right]^{-}$clusters and $\left[\mathrm{Cu}_{4} \mathrm{Br}_{3}\right]_{n}{ }^{n+}$ chains. Anorg. Allg. Chem. 2014, 640, 1462-1466. [CrossRef] 